\title{
Caracterização bromatológica de silagens de milho de genótipos super precoce
}

\author{
Chemical characterization of corn silage
}

\begin{abstract}
Valmir da Cunha Vieira ${ }^{\mathrm{I}}$ Thomas Newton Martin $^{\mathrm{II}}$ Luis Fernando Glasenapp de Menezes ${ }^{\mathrm{III}}$ Sidney Ortiz ${ }^{\mathrm{III}}$ Patricia Bertoncelli ${ }^{\mathrm{II}}$ Lindolfo Storck ${ }^{\mathrm{I}}$
\end{abstract}

\section{RESUMO}

A disponibilização anual de genótipos de milho é grande, sendo necessária uma adequada avaliação desses genótipos para serem indicados para a produção de silagem. Objetivou-se avaliar as características bromatológicas da silagem produzida a partir de diferentes genótipos de milho, bem como, avaliar se a base genética ou a dureza dos grãos podem alterar a indicação de genótipos de milho para silagem. O experimento foi realizado na área experimental da Universidade Tecnológica Federal do Paraná, no delineamento blocos completos ao acaso, avaliandose os 30 genótipos do ensaio Sul Super Precoce, organizado pela Embrapa. Avaliaram-se as características bromatológicas da silagem produzida com os diferentes genótipos, posteriormente eles foram agrupados segundo a base genética e a textura dos grãos. Verificou-se que os genótipos do ensaio Sul Super Precoce não podem ser diferenciados segundo a base genética ou a textura dos grãos para todas as características avaliadas. Porém, eles podem ser diferenciados pela matéria seca da silagem.

Palavras-chave: base genética, dureza do grão, indicação de cultivares, forragem conservada.

\section{ABSTRACT}

The annual availability of corn genotype is very large, requiring a proper assessment to be indicated for the production of silage. The aim of this study was to evaluate the chemical characteristics of corn genotypes for silage production, and assess whether the grain genetic basis or hardness may change the indication of corn cultivars for silage. The experiment was conducted at the experimental area of the Universidade Tecnológica Federal of Paraná, in the randomized block design, evaluating 30 genotypes of experiment Super Early South. It was evaluated the chemical characteristics of the genotypes and, after they were grouped according to the characteristics of genetic basis and of grain texture. It was found that the genotypes of the experiment South Super Early cannot be differentiated according to the genetic basis of grain and texture for all traits. However, they can be distinguished by the dry matter silage.

Key words: genetic basis, grain hardness, indicated cultivars, forage conserved.

\section{INTRODUÇÃO}

A qualidade forrageira das pastagens é alterada em função do vazio forrageiro, reduzindo quali-quantitativamente a sua composição bromatológica. Nesse sentido, a expressão do potencial zootécnico na região Sul somente é possível a partir da melhoria das pastagens ou suplementação com forragens conservadas. A silagem é a produção de alimento conservado mais difundido nos sistemas de produção de carne e leite, objetivando atender a demanda de volumoso em quantidade e qualidade nos períodos de baixa produção de matéria seca das pastagens. O milho é a cultura mais utilizada (MELLO \& NÖRNBERG, 2004), devido as suas características (BAL et al., 2000; BELEZE et al., 2003).

Uma grande quantidade de genótipos de milho é disponibilizada à comercialização todos os anos. Na safra 2009/2010, foram disponibilizados 325 genótipos convencionais e 104 transgênicos, havendo genótipos com recomendação para produção de silagem. Diversos autores têm observado a existência de variabilidade tanto para a produtividade

IUniversidade Tecnológica Federal do Paraná (UTFPR), Campus Pato Branco, Pato Branco, PR, Brasil.

IIDepartamento de Fitotecnia, Universidade Federal de Santa Maria (UFSM), 97105-900, Santa Maria, RS, Brasil. E-mail: martin.ufsm@gmail.com.

*Autor para correspondência.

IIIPrograma de Pós-graduação em Zootecnia, UTFPR, Campus Dois Vizinhos, Dois Vizinhos, PR, Brasil. 
de matéria seca, produção de grãos, digestibilidade e para a qualidade da silagem (OLIVEIRA et al., 2007; VILELA et al., 2008). Essas características são afetadas pela interação genótipos $\mathrm{x}$ ambiente, sendo necessária a avaliação em diferentes locais. Essa interação dificulta a recomendação de genótipos, pois pode haver diferentes comportamentos dos genótipos de acordo com o local de cultivo (MITTELMANN et al., 2005; NEUMANN et al., 2008). BALBINOT \& FLECK (2005) observaram que houve diferença significativa na produção entre genótipos de grupos genéticos (híbrido simples versus variedade), devido as suas diferenças morfológicas (variedade com estatura elevada e folhas mais horizontais, e o híbrido simples com estatura baixa e folhas eretas) quando submetidos a diferentes espaçamentos.

Várias pesquisas vêm sendo desenvolvidas objetivando determinar quais os genótipos com melhores características fitomorfológicas e bromatológicas de interesse para a produção de silagem, direcionamento do sistema produtivo na busca de melhores resultados (BELEZE et al., 2003; JAREMTCHUK et al., 2005). Dessa forma, o objetivo deste trabalho foi verificar se os genótipos de milho podem ser agrupados pela base genética ou pela textura do grão, visando a sua indicação para a fabricação de silagem, bem como avaliar as características bromatológicas da silagem produzida a partir de diferentes genótipos.

\section{MATERIAL E MÉTODOS}

O experimento foi conduzido na área experimental da Universidade Tecnológica Federal do Paraná (UTFPR), campus Dois Vizinhos. A região compreende o terceiro Planalto Paranaense, com altitude de $520 \mathrm{~m}$, latitude de $25^{\circ} 44^{\prime \prime}$ Sul e longitude de $53^{\circ} 04^{\prime \prime}$ Oeste. O clima predominante é do tipo subtropical úmido mesotérmico (Cfa), segundo a classificação de Köppen (MAACK, 1968). O solo pertence à unidade de mapeamento Nitossolo Vermelho Distroférrico Úmbrico, textura argilosa fase floresta subtropical perenifólia, relevo ondulado (SANTOS et al., 2008).

O presente estudo usou os 30 genótipos de milho, representativos de ciclo super precoce, referentes ao ensaio de competição de cultivares organizado pela Embrapa Milho e Sorgo (Tabela 1). O experimento foi implantado no dia 27 de outubro de 2009, colocando-se duas sementes por cova, realizando posteriormente o desbaste (20/11/2009), quando as plantas apresentavam de duas a três folhas definitivas, ajustando-se o estande para 63.000 plantas por hectare. As parcelas foram compostas por duas fileiras de cinco metros de comprimento, espaçadas 75 centímetros entre fileiras e aproximadamente 4,3 plantas por metro linear. O delineamento foi blocos completos ao acaso com duas repetições. A adubação de base consistiu de $20 \mathrm{~kg} \mathrm{ha}^{-1}$ de ureia, $100 \mathrm{~kg} \mathrm{ha}^{-1}$

Tabela 1 - Nome comercial, base genética $\left(\mathrm{BG}^{*}\right)$, dureza do grão (DG**), empresa produtora (EMP***) dos genótipos pertencentes ao ensaio Sul Super Precoce.

\begin{tabular}{|c|c|c|c|c|c|c|c|}
\hline Nome comercial & BG & DG & EMP & Nome Comercial & BG & DG & EMP \\
\hline AS1555YG & HS & $\mathrm{D}$ & AGR & HPS3516A08 & HT & SD & EMB \\
\hline AS1572YG & HS & NI & AGR & EMB.Gorutuba & VAR & NI & EMB \\
\hline 30A37 & HS & $\mathrm{DM}$ & AGN & EMB.Sintético & NI & SD & EMB \\
\hline 30A77 & HS & SD & AGN & GNZX0729 & HS & $\mathrm{DM}$ & GNZ \\
\hline 20A78 & HT & $\mathrm{SD}$ & AGN & 32R48Y & HS & $\mathrm{SD}$ & PS \\
\hline ВMX819 & HT & SD & $\mathrm{BIO}$ & PREX12S12 & HS & SD & PR \\
\hline Dx 908 & HS & NI & DEL & PREX22S11 & HS & $\mathrm{SD}$ & PR \\
\hline Dx 603 & HT & $\mathrm{SD}$ & DEL & PREX22T10 & $\mathrm{HT}$ & $\mathrm{SD}$ & PR \\
\hline 2A550 & HS & $\mathrm{SD}$ & DAS & PREXT0109 & $\mathrm{HT}$ & $\mathrm{SD}$ & PR \\
\hline 2B587 & HS & SD & DAS & PREX22D11 & HD & $\mathrm{D}$ & PR \\
\hline 2B433 & HT & SD & DAS & SHS-7090 & HS & $\mathrm{SD}$ & SHS \\
\hline AL2007A & VAR & $\mathrm{SD}$ & CATI & SHS-7111 & HS & NI & SHS \\
\hline H2002ALTA & $\mathrm{HI}$ & $\mathrm{SD}$ & CATI & P32R22(Test) & HS & NI & EMB \\
\hline H25ALTA & $\mathrm{HI}$ & $\mathrm{SD}$ & CATI & 2A106(Test) & HS & NI & EMB \\
\hline EMBRAPA1F640 & HS & SD & EMB & AG6018(Test) & HT & NI & EMB \\
\hline
\end{tabular}

* Base Genética: HS - Híbrido Simples, HT - Híbrido Triplo, Var - Variedade, HD - Híbrido Duplo, HI - Híbrido Intervarietal; **Dureza do grão: NI - Não informado, SD - Semi Duro, D - Duro, DM - Dentado Mole; *** Empresas: Agroeste (AGR); Embrapa (EMB); Não informado (NI); DI SOLO (DX); Santa Helena Sementes (SHS); Pioneer Sementes (PS); Agromen Tecnologia (AGN); Gênesis Sementes (GNZ); Dow AgroSciences (DAS); DSMM/CATI (CATI), Biogene (BIO), Delta (DEL) e Prezzoto (PR). 
de super fosfato simples e $20 \mathrm{~kg} \mathrm{ha}^{-1}$ de cloreto de potássio. A adubação de cobertura foi realizada quando as plantas apresentavam cinco a seis folhas expandidas, utilizando-se $80 \mathrm{~kg}_{\text {ha }}{ }^{-1}$ de nitrogênio na forma de ureia. O controle de plantas daninhas foi realizado com aplicação do herbicida (6-cloro- $\mathrm{N}^{2}$ etil-isopropil-1,3,5-triazina-2,4-diamina Triazina) na dosagem 5,0L ha-1 . O inseticida utilizado foi (S-metil$\mathrm{N}$ (metilcarbamoil)-oxi)-tioacetimidato)Methomyl) na dosagem $0,3 \mathrm{~L} \mathrm{ha}{ }^{-1}$. O experimento foi conduzido sem que plantas daninhas, pragas e doenças tenham prejudicado o desenvolvimento da cultura do milho, resultado do controle químico aplicado.

O ponto de colheita foi determinado quando os grãos da espiga apresentavam-se no estádio pastoso a farináceo. Um dia antes do início da colheita (22/01/2010), foram avaliadas a estatura das plantas (EP, m), a estatura de inserção da primeira espiga $(E E, m)$ e contado o número de plantas da parcela (NP). A colheita consistiu no corte das plantas de uma fileira de cinco metros de comprimento, a $30 \mathrm{~cm}$ da superfície do solo, em cada parcela. As plantas, depois de colhidas, foram pesadas em balança digital para determinação da matéria verde (MV, $\mathrm{t}$ $\left.\mathrm{ha}^{-1}\right)$. Uma das plantas foi separada para as avaliações fitotécnicas do teor de matéria seca de espiga (MSE, \%) e teor de matéria seca de planta (MSP, \%). O restante do material foi triturado com regulagem de $5 \mathrm{~mm}$, utilizando ensiladeira acoplada em um trator. Após trituração do material, retirou-se uma amostra para determinação da massa seca da silagem (MS, t ha ${ }^{-1}$ ), usando uma estufa de circulação forçada a $55^{\circ} \mathrm{C}$ até massa constante. A silagem foi realizada em silos experimentais de $500 \mathrm{~mm}$ de comprimento por 100mm de diâmetro, contendo $350 \mathrm{~g}$ de areia no fundo do silo. A compactação foi realizada manualmente, numa densidade de $550 \mathrm{~kg}$ de matéria verde por $\mathrm{m}^{-3}$. O material permaneceu ensilado por 60 dias.

As características bromatológicas da silagem foram avaliadas por meio da análise química, segundo Compêndio de alimentação animal Sindirações (ANFAR, 2009), sendo elas: potencial de hidrogênio $(\mathrm{pH})$, teor de matéria seca da silagem (MSS, \%), proteína bruta (PB, \%), extrato etéreo (EE, $\%)$, material mineral (MM, \%), fibra em detergente neutro (FDN, \%) e fibra em detergente ácido (FDA, $\%)$. Os nutrientes digestíveis totais (NDT, \%) e energia líquida de lactação (ELL, kcal kg de $\mathrm{MS}^{-1}$ ) foram estimados de acordo com HARLAN et al. (1991): $\mathrm{ELL}=(1,044-(0,0124 *$ FDA $)) * 2,2$ e

$$
N D T=\left(53,1 *\left(\frac{E L L}{2,2}\right)\right)+31,4 \text {. }
$$

Foi procedida a análise de variância, sendo os genótipos comparados por contrastes entre as diferentes bases genéticas (híbrido simples, híbrido triplo, híbrido duplo, híbrido intervarietal e variedade cultivada), usando o teste de Scheffé $(\mathrm{P}=0,05)$, assim como se testou os contrastes entre os genótipos de diferentes texturas dos grãos (duro, semiduro, dentado). Para comparar os genótipos, individualmente, aplicou-se o teste de Scott-Knott $(\mathrm{P}=0,05)$.

\section{RESULTADOS E DISCUSSÃO}

Analisando-se as estimativas dos contrastes entre os genótipos de diferentes bases genéticas, não se verificam características que apresentam significância (Tabela 2). Dessa forma, a indicação de genótipos para produção de silagem não pode ser realizada pela base genética. Isso também ocorre ao analisar as estimativas dos contrastes entre as classes de texturas dos grãos (Tabela 3). Então, para os trintas genótipos avaliados, nem o agrupamento dos genótipos pela base genética ou pela textura de grãos é capaz de indicar um grupo superior aos demais. Situação semelhante foi observada por ROSSI JÚNIOR et al. (2006) quando avaliaram dois híbridos de diferentes textura de grãos (dentado e semidentado). A textura dos grãos de milho são definidos pelas empresas produtoras de sementes, dessa forma, toma-se por base essas definições, inferindose que essas características sejam verdadeiras para a recomendação dos usos de cada genótipo. Estes autores não obtiveram diferença significativa para os caracteres bromatológicos da silagem (matéria seca, proteína bruta, fibra em detergente neutro e fibra em detergente ácido), porém para a digestibilidade verificaram significância. Considera-se que nesse sentido também haja uma variabilidade dentro de cada grupo de textura de grão. Avaliando genótipos de milho, MORAES et al. (2008) verificaram que o híbrido de textura dentada possui maior produção de massa seca que os híbridos de textura dura (18.829 e $20.400 \mathrm{~kg} \mathrm{ha}^{-1}$, respectivamente). Resultados semelhantes (18.092 a $23.869 \mathrm{~kg} \mathrm{ha}^{-1}$ ) foram obtidos por FLARESSO et al. (2000).

Alguns autores (DELALIBERA et al., 2008; CORRÊA et al., 2002; MORAES et al., 2008) verificaram diferença entre grupos de genótipos quanto a texturas, porém os autores sempre trabalharam com um grupo restrito de genótipos. Além disso, destacam que a magnitude da diferença é proporcional ao número de genótipos dentro de cada grupo de textura de grãos. Essa informação é relevante, pois grande parte dos estudos envolvem um número restrito de genótipos, que na maioria das vezes é menor que os 
Tabela 2 - Estimativas das diferenças entre os genótipos de duas bases genéticas (HS*, HT, HD, HI e Var) e diferença mínima significativa do contraste (teste Scheffé com $\mathrm{P}=0,05$; DMS**) referente a diferentes caracteres dos genótipos do ensaio Sul Super Precoce.

\begin{tabular}{|c|c|c|c|c|c|c|c|c|c|c|}
\hline Caracter & HS - HT & DMS & HS - HD & DMS & HS - Var & DMS & HS - HI & DMS & HT - HD & DMS \\
\hline EP & 0,00 & 0,40 & $-0,20$ & 0,90 & 0,10 & 0,60 & $-0,10$ & 0,60 & $-0,20$ & 0,90 \\
\hline $\mathrm{EE}$ & 0,00 & 0,20 & 0,00 & 0,40 & 0,20 & 0,30 & $-0,10$ & 0,30 & 0,00 & 0,40 \\
\hline MV & $-0,50$ & 21,50 & 4,70 & 48,80 & 13,20 & 35,50 & $-7,40$ & 35,50 & 5,20 & 50,60 \\
\hline MSE & $-2,40$ & 10,00 & 0,90 & 20,00 & 0,20 & 20,00 & 2,40 & 20,00 & 3,10 & 30,00 \\
\hline MSP & $-2,60$ & 10,00 & $-0,40$ & 10,00 & $-2,30$ & 10,00 & 2,40 & 10,00 & 2,20 & 20,00 \\
\hline MS & $-0,90$ & 11,70 & 2,60 & 26,60 & 6,20 & 19,40 & $-5,10$ & 19,40 & 3,50 & 27,70 \\
\hline $\mathrm{pH}$ & $-0,10$ & 1,00 & 0,40 & 2,20 & 0,40 & 1,60 & 0,30 & 1,60 & 0,50 & 2,30 \\
\hline MSS & $-1,50$ & 14,90 & 2,60 & 33,90 & 3,80 & 24,70 & $-3,90$ & 24,70 & 4,10 & 35,10 \\
\hline PB & $-0,10$ & 2,10 & $-0,70$ & 4,90 & $-0,20$ & 3,60 & $-0,10$ & 3,60 & $-0,60$ & 5,10 \\
\hline $\mathrm{EE}$ & 0,00 & 1,60 & 0,20 & 3,60 & 0,90 & 2,60 & 0,20 & 2,60 & 0,20 & 3,70 \\
\hline MM & 0,10 & 2,00 & 0,40 & 4,60 & $-0,10$ & 3,40 & 0,00 & 3,40 & 0,30 & 4,80 \\
\hline FDN & $-0,90$ & 12,70 & $-7,10$ & 29,00 & $-6,60$ & 21,10 & $-7,80$ & 21,10 & $-6,20$ & 30,10 \\
\hline FDA & $-2,10$ & 11,60 & $-1,70$ & 26,40 & $-2,00$ & 19,20 & $-8,90$ & 19,20 & 0,40 & 27,40 \\
\hline NDT & 1,30 & 7,50 & 1,10 & 17,00 & 1,30 & 12,40 & 7,20 & 12,40 & $-0,20$ & 17,60 \\
\hline \multirow[t]{2}{*}{ ELL } & 0,00 & 0,30 & 0,00 & 0,70 & 0,00 & 0,50 & 0,20 & 0,50 & 0,00 & 0,70 \\
\hline & HT - VAR & DMS & HT - HI & DMS & HD - VAR & DMS & HD - HI & DMS & VAR - HI & DMS \\
\hline EP & 0,10 & 0,70 & $-0,10$ & 0,70 & 0,30 & 1,10 & 0,10 & 1,10 & $-0,20$ & 0,90 \\
\hline $\mathrm{EE}$ & 0,20 & 0,30 & $-0,10$ & 0,30 & 0,20 & 0,50 & $-0,10$ & 0,50 & $-0,30$ & 0,40 \\
\hline MV & 13,70 & 37,90 & $-6,90$ & 37,90 & 8,50 & 57,90 & $-12,10$ & 57,90 & $-20,60$ & 47,30 \\
\hline MSE & 2,50 & 20,00 & 4,80 & 19,10 & $-0,70$ & 30,00 & 0,00 & 30,00 & 2,30 & 20,00 \\
\hline MSP & 0,30 & 10,00 & 5,00 & 11,40 & $-1,90$ & 20,00 & 2,80 & 20,00 & 4,70 & 10,00 \\
\hline MSP & 7,10 & 20,70 & $-4,20$ & 20,70 & 3,62 & 31,70 & $-7,70$ & 31,70 & $-11,30$ & 25,90 \\
\hline $\mathrm{EF}$ & $-2,00$ & 2,40 & 0,60 & 2,40 & $-3,20$ & 2,40 & 0,20 & 2,40 & 2,60 & 2,90 \\
\hline $\mathrm{pH}$ & 0,50 & 1,70 & 0,40 & 1,70 & 0,00 & 2,70 & $-0,10$ & 2,70 & $-0,10$ & 2,20 \\
\hline MSS & 5,30 & 26,40 & $-2,40$ & 26,30 & 1,20 & 40,30 & $-6,50$ & 40,30 & $-7,70$ & 32,90 \\
\hline PB & $-0,10$ & 3,80 & 0,00 & 3,90 & 0,50 & 5,80 & 0,60 & 5,80 & 0,10 & 4,70 \\
\hline $\mathrm{EE}$ & 0,90 & 2,80 & 0,20 & 2,80 & 0,70 & 4,30 & 0,00 & 4,30 & $-0,70$ & 3,50 \\
\hline MM & $-0,20$ & 3,60 & $-0,10$ & 3,60 & $-0,50$ & 5,50 & $-0,40$ & 5,50 & 0,10 & 4,50 \\
\hline FDN & $-5,70$ & 22,50 & $-6,90$ & 22,50 & 0,50 & 34,40 & $-0,70$ & 34,40 & $-1,20$ & 28,10 \\
\hline FDA & 0,10 & 20,50 & $-6,80$ & 20,50 & $-0,30$ & 31,40 & $-7,20$ & 31,40 & $-6,90$ & 25,60 \\
\hline NDT & 0,00 & 13,20 & 5,90 & 13,20 & 0,20 & 20,20 & 6,10 & 20,20 & 5,90 & 16,50 \\
\hline ELL & 0,00 & 0,60 & 0,20 & 0,60 & 0,00 & 0,90 & 0,20 & 0,90 & 0,20 & 0,60 \\
\hline
\end{tabular}

* HS: híbrido simples; HT: híbrido triplo; HD: híbrido duplo; HI: híbrido intervarietal; VAR: variedade cultivada, **DMS para as variáveis: Estatura de planta (EP, m), estatura de inserção da primeira espiga (EE, m), teor de matéria seca de espiga (MSE, \%), teor de matéria seca de planta (MSP, \%), massa seca (MS, t ha ${ }^{-1}$ ), teor de matéria seca da silagem (MSS, \%), proteína bruta (PB, \%), extrato etéreo (EE, \%), matéria mineral (MM, \%), fibra detergente neutro (FDN, \%), fibra detergente ácido (FDA, \%), nutrientes digestíveis totais (NDT, \%), energia líquida de lactação (ELL, kcal kg-1 MS).

11 genótipos testado pelo autor, ou no presente estudo. Estudo com maior quantidade de genótipos por grupo de textura possuem maior representatividade no que diz respeito aos genótipos disponíveis no mercado de sementes. O que pode acontecer quando se avaliam um número mais representativo de genótipos, é que dentro do grupo (genótipos de texturas iguais) não há uma variabilidade baixa, havendo genótipos que se sobrepõem aos resultados de outros grupos e que, na média, podem não diferir. A variabilidade entre grupos deveria ser maximizada, mas isso não ocorre, impossibilitando indicar grupos superiores aos demais. A comparação entre grupos com a mesma base genética é mais frequente em relação a textura dos grãos. Porém, bases genéticas distintas possuem exigências peculiares em relação ao manejo, indicando assim uma forte interação genótipo versus ambiente.

O número de plantas por parcela foi homogêneo ( $\mathrm{CV}=7,74 \%$ ), estimando em média uma população de 58.148 plantas ha-1 (dados apresentados parcialmente). Houve diferença significativa $(\mathrm{P}=0,05)$ entre os genótipos apenas para o teor de matéria seca (MSS, \%) (Tabela 4). A variabilidade das características avaliadas para cultura do milho pode ser observado por diversos autores (OLIVEIRA 
Tabela 3 - Estimativas das diferenças entre os genótipos de duas classes de textura de grãos (*SD, D e DM) e diferença mínima significativa do contraste (teste Scheffé com $\mathrm{P}=0,05$; DMS**) referente a diferentes caracteres dos genótipos do ensaio Sul Super Precoce.

\begin{tabular}{|c|c|c|c|c|c|c|}
\hline Caracter & SD - D & DMS & SD - DM & DMS & D - DM & DMS \\
\hline EP & 0,00 & 0,60 & 0,00 & 0,60 & 0,00 & 0,90 \\
\hline $\mathrm{EE}$ & 0,10 & 0,30 & 0,00 & 0,30 & $-0,10$ & 0,40 \\
\hline MV & $-6,60$ & 35,20 & 5,70 & 35,20 & 12,30 & 47,30 \\
\hline MSE & 3,30 & 20,00 & 1,80 & 20,00 & $-1,60$ & 20,00 \\
\hline MSP & 4,80 & 10,00 & 1,70 & 10,00 & $-3,10$ & 10,00 \\
\hline MS & 2,00 & 19,20 & 5,00 & 19,20 & 3,00 & 25,90 \\
\hline $\mathrm{pH}$ & $-0,20$ & 1,60 & $-0,40$ & 1,60 & $-0,20$ & 2,20 \\
\hline MSS & 7,00 & 24,40 & 5,70 & 24,40 & $-1,30$ & 32,90 \\
\hline PB & 0,30 & 3,50 & 0,10 & 3,50 & $-0,20$ & 4,70 \\
\hline $\mathrm{EE}$ & 0,10 & 2,60 & $-0,10$ & 2,60 & $-0,20$ & 3,50 \\
\hline MM & $-1,20$ & 3,40 & 0,10 & 3,40 & 1,30 & 4,50 \\
\hline FDN & 0,70 & 20,90 & 4,50 & 20,90 & 3,80 & 28,10 \\
\hline FDA & 0,00 & 19,00 & $-0,40$ & 19,00 & $-0,40$ & 25,60 \\
\hline NDT & $-0,10$ & 12,30 & 0,20 & 12,30 & 0,30 & 16,50 \\
\hline ELL & 0,00 & 0,50 & 0,00 & 0,50 & 0,00 & 0,70 \\
\hline
\end{tabular}

* SD: Semi-duro; D: duro; DM: dentado mole; **DMS para as variáveis: Estatura de planta (EP, m), estatura de inserção da primeira espiga $(\mathrm{EE}, \mathrm{m})$, teor de matéria seca de espiga (MSE, \%), teor de matéria seca de planta (MSP, \%), massa seca (MS, $\mathrm{t}^{-1}$ ), teor de matéria seca da silagem (MSS, \%), proteína bruta (PB, \%), extrato etéreo (EE, \%), matéria mineral (MM, \%), fibra detergente neutro (FDN, \%), fibra detergente ácido (FDA, \%), nutrientes digestíveis totais (NDT, \%), energia líquida de lactação (ELL, $\mathrm{kcal} \mathrm{kg}^{-1} \mathrm{MS}$ ).

et al., 2004; SENGER et al., 2005). A variação nos teores de extrato etéreo não pode ser observada neste trabalho, havendo genótipos com baixa MS e com teores de extrato etéreo dentro da faixa normalmente observada nos trabalhos (SENGER et al., 2005; ROSSI JÚNIOR et al., 2006).

O teor de matéria seca apresentada pelos 30 genótipos (24,1 a 50,5\%) estão próximos aos valores apresentados por NEUMANN et al. (2008), que encontraram variabilidade de 33,5 a $40,4 \%$, assim como os teores de proteína bruta (7,55\%), estão de acordo com os valores encontrados por JAREMTCHUCK et al. (2005) e VILELA et al. (2008). A variabilidade do teor de matéria seca ocorreu devido alguns genótipos possuírem os grãos no ponto de ensilagem, porém colmos e folhas apresentam diferentes graus de maturação entre os genótipos de milho. E como a colheita foi regulada pelo grau de maturidade dos grãos, houve essa variabilidade entre os genótipos. Dentre as variáveis bromatológicas analisadas, o pH não diferiu para os diferentes genótipos, com média de 3,86 (dados apresentados parcialmente).

As frações fibrosas (FDN e FDA) tiveram os valores de $57,43 \%$ e $29,29 \%$ respectivamente, e encontram-se dentro da faixa observada nos trabalhos de SILVA et al. (2005), com FDN de 51,49 a 64,14\% e FDA de 30,27 a 35,69\% e SENGER et al. (2005) com FDN entre 50,6 e 63,9\% e FDA entre 28 e
39,3\%. A FDN constitui o parâmetro mais usado para o balanceamento de dietas uma vez que interfere na qualidade da mesma. Esses parâmetros FDN e FDA, em maiores ou menores proporções, afetam quatro características dos alimentos importantes na nutrição animal: digestibilidade e valor energético, com a fermentação ruminal e pode estar envolvida no controle da ingestão de alimento (MERTENS, 1992).

Os nutrientes digestíveis totais (NDT), tiveram média de 67,46\%, com valor mínimo de 60,27 e máximo de $71,45 \%$, estão próximos aos valores obtidos por JAREMTCHUCK et al. (2005). Dessa forma, as principais características relacionadas com a qualidade da silagem, obtidas nesse estudo, estão de acordo com os resultados da literatura. A escolha do genótipo deve ser determinado pelo teor de matéria seca, onde os genótipos 30A77, 2A550, 2B587, H25Alta, HPS16A08, e PREX22T10 possuem os valores significativamente superiores aos demais. Todos esses genótipos são de textura semi-dura.

\section{CONCLUSÃO}

A escolha do genótipo para produção de silagem não pode ser realizada por meio de grupos de bases genéticas ou grupos de textura de grãos. A característica que apresentou diferença significativa entre os genótipos foi o teor de matéria seca da silagem. 
Tabela 4 - Média de variáveis fitotécnicas e bromatológicas obtidas em diferentes genótipos de milho do ensaio Sul Super Precoce utilizados para a confecção de silagem (substituir número genótipo por nome comercial).

\begin{tabular}{|c|c|c|c|c|c|c|c|c|c|c|c|c|c|c|c|}
\hline Genótipo & $\mathrm{EP}$ & $\mathrm{EE}$ & MV & MSE & MSP & MS & MSS & & PB & $\mathrm{EE}$ & $\mathrm{MM}$ & FDN & FDA & NDT & ELL \\
\hline AS1555YG & 2,3 & 1,1 & 65,0 & 45,4 & 27,7 & 19,0 & 29,3 & $\mathrm{~b}^{+}$ & 6,8 & 2,6 & 3,4 & 58,7 & 27,6 & 68,7 & 1,5 \\
\hline AS1572YG & 2,4 & 1,2 & 57,3 & 38,9 & 30,2 & 16,5 & 28,9 & $\mathrm{~b}$ & 7,9 & 3,6 & 3,7 & 59,9 & 29,7 & 67,3 & 1,5 \\
\hline 30A37 & 2,2 & 1,2 & 50,0 & 46,4 & 29,9 & 14,9 & 29,5 & $\mathrm{~b}$ & 8,1 & 3,2 & 3,8 & 56,0 & 32,1 & 65,7 & 1,4 \\
\hline 30A77 & 2,2 & 1,1 & 57,5 & 51,5 & 35,3 & 21,9 & 38,4 & $\mathrm{a}$ & 7,5 & 3,4 & 3,1 & 51,2 & 23,4 & 71,5 & 1,7 \\
\hline $20 A 78$ & 2,2 & 1,1 & 48,8 & 56,7 & 39,9 & 17,1 & 34,6 & $\mathrm{~b}$ & 7,8 & 2,8 & 4,2 & 61,3 & 32,5 & 65,4 & 1,4 \\
\hline BMX819 & 2,1 & 1,1 & 47,8 & 56,1 & 34,6 & 14,9 & 30,5 & $\mathrm{~b}$ & 8,0 & 3,3 & 3,6 & 57,0 & 26,5 & 69,4 & 1,6 \\
\hline Dx 908 & 2,3 & 1,4 & 54,8 & 52,3 & 35,4 & 16,3 & 28,8 & $\mathrm{~b}$ & 7,0 & 3,9 & 2,6 & 54,4 & 28,8 & 67,9 & 1,5 \\
\hline Dx 603 & 2,2 & 1,2 & 50,2 & 57,4 & 40,6 & 14,4 & 28,7 & $\mathrm{~b}$ & 6,7 & 2,6 & 4,4 & 60,0 & 35,2 & 63,7 & 1,3 \\
\hline 2A550 & 2,2 & 1,1 & 53,5 & 51,4 & 36,9 & 26,6 & 49,6 & $\mathrm{a}$ & 7,5 & 2,7 & 4,4 & 55,7 & 24,8 & 70,5 & 1,6 \\
\hline 2B587 & 2,3 & 1,1 & 50,5 & 50,2 & 33,4 & 21,2 & 42,4 & $\mathrm{a}$ & 7,5 & 3,2 & 2,8 & 54,9 & 24,9 & 70,4 & 1,6 \\
\hline 2B433 & 2,2 & 1,2 & 48,9 & 50,2 & 32,8 & 15,5 & 31,8 & $\mathrm{~b}$ & 7,3 & 3,6 & 3,5 & 47,7 & 24,5 & 70,7 & 1,6 \\
\hline AL2007A & 2,2 & 1,1 & 44,3 & 44,9 & 34,7 & 10,8 & 24,1 & $\mathrm{~b}$ & 6,8 & 1,9 & 3,9 & 65,0 & 32,6 & 65,4 & 1,4 \\
\hline H2002Alta & 2,2 & 1,2 & 60,3 & 48,7 & 29,2 & 17,2 & 28,3 & $\mathrm{~b}$ & 7,3 & 3,0 & 4,1 & 62,3 & 40,3 & 60,3 & 1,2 \\
\hline H25Alta & 2,4 & 1,3 & 57,4 & 46,3 & 33,0 & 26,4 & 44,1 & $\mathrm{a}$ & 7,9 & 2,8 & 3,4 & 65,4 & 33,7 & 61,9 & 1,4 \\
\hline Embr.F640 & 2,5 & 1,3 & 75,0 & 51,5 & 35,5 & 24,2 & 32,3 & $\mathrm{~b}$ & 7,9 & 3,4 & 4,1 & 54,5 & 25,4 & 70,1 & 1,6 \\
\hline HPS3516A08 & 2,4 & 1,2 & 53,7 & 53,1 & 39,2 & 20,4 & 37,8 & $\mathrm{a}$ & 7,4 & 2,8 & 2,8 & 58,0 & 28,7 & 67,9 & 1,5 \\
\hline Gorutuba & 2,1 & 0,9 & 32,1 & 54,7 & 37,0 & 10,2 & 33,0 & $\mathrm{~b}$ & 8,5 & 2,6 & 3,9 & 60,5 & 27,7 & 68,6 & 1,5 \\
\hline Emb.Sintético & 2,3 & 1,1 & 43,2 & 50,9 & 32,9 & 13,2 & 30,6 & $\mathrm{~b}$ & 7,6 & 3,7 & 3,6 & 52,1 & 25,0 & 70,4 & 1,6 \\
\hline GNZX0729 & 2,2 & 1,2 & 38,7 & 45,5 & 33,9 & 11,5 & 29,3 & $\mathrm{~b}$ & 7,6 & 3,3 & 4,2 & 60,7 & 31,3 & 66,2 & 1,4 \\
\hline 32R48Y20 & 2,2 & 1,2 & 41,3 & 52,2 & 36,5 & 10,4 & 27,3 & $\mathrm{~b}$ & 6,7 & 3,1 & 3,4 & 51,9 & 27,8 & 68,5 & 1,5 \\
\hline PREX12S12 & 2,0 & 1,1 & 49,6 & 49,9 & 32,3 & 14,1 & 28,4 & $\mathrm{~b}$ & 7,4 & 2,1 & 4,0 & 61,6 & 32,2 & 65,6 & 1,4 \\
\hline PREX22S11 & 2,1 & 1,1 & 40,9 & 52,3 & 32,8 & 12,1 & 28,8 & $\mathrm{~b}$ & 6,8 & 3,2 & 3,5 & 57,3 & 28,5 & 68,1 & 1,5 \\
\hline PREX22T10 & 2,3 & 1,2 & 52,8 & 44,4 & 33,6 & 26,7 & 50,5 & $\mathrm{a}$ & 7,5 & 2,9 & 3,8 & 66,4 & 38,9 & 61,2 & 1,2 \\
\hline PREXT0109 & 2,4 & 1,3 & 59,3 & 49,3 & 36,8 & 18,7 & 31,4 & $\mathrm{~b}$ & 8,0 & 3,5 & 3,0 & 48,6 & 23,6 & 71,3 & 1,7 \\
\hline PREX22D11 & 2,4 & 1,2 & 46,7 & 49,1 & 33,9 & 14,1 & 29,7 & $\mathrm{~b}$ & 8,2 & 2,9 & 3,4 & 63,2 & 29,8 & 67,2 & 1,5 \\
\hline SHS-7090 & 2,2 & 1,1 & 50,8 & 50,0 & 32,5 & 12,6 & 25,0 & $\mathrm{~b}$ & 7,5 & 3,2 & 6,3 & 56,8 & 31,3 & 66,2 & 1,4 \\
\hline SHS-7111 & 2,1 & 1,1 & 60,2 & 60,5 & 36,5 & 19,9 & 33,0 & $\mathrm{~b}$ & 7,1 & 3,5 & 3,5 & 55,6 & 25,0 & 70,4 & 1,6 \\
\hline P32R22 & 2,2 & 1,1 & 40,4 & 45,1 & 29,7 & 12,3 & 30,5 & $\mathrm{~b}$ & 8,6 & 2,8 & 3,1 & 56,0 & 29,1 & 67,7 & 1,5 \\
\hline 2A106 & 2,3 & 1,1 & 37,5 & 55,7 & 37,2 & 13,4 & 35,9 & $\mathrm{~b}$ & 8,1 & 3,4 & 4,4 & 52,4 & 27,9 & 68,6 & 1,5 \\
\hline AG6018 & 2,2 & 1,0 & 55,5 & 52,1 & 34,3 & 15,6 & 28,9 & $\mathrm{~b}$ & 7,6 & 3,0 & 3,4 & 58,1 & 30,2 & 67,0 & 1,5 \\
\hline Média & 2 & 1,1 & 50 & 50,6 & 34,1 & 15,6 & 30,5 & & 7,5 & 3,2 & 3,6 & 57,2 & 28,8 & 67,9 & 1,5 \\
\hline $\mathrm{CV}$ & 5 & 5 & 18 & 9,1 & 9,1 & 28,9 & 19,9 & & 6,93 & 14,9 & 18,8 & 8,3 & 14,4 & 4,3 & 7,7 \\
\hline
\end{tabular}

+Genótipos com médias não seguidas pela mesma letra diferem pelo teste de Scott-Knott $(\mathrm{P}=0,05)$;

* Estatura de planta (EP, m), estatura de inserção da primeira espiga (EE, m), teor de matéria seca de espiga (MSE, \%), teor de matéria seca de planta (MSP, \%), massa seca (MS, $\mathrm{t} \mathrm{ha}^{-1}$ ), teor de matéria seca da silagem (MSS, \%), proteína bruta (PB, \%), extrato etéreo (EE, \%), matéria mineral (MM, \%), fibra detergente neutro (FDN, \%), fibra detergente ácido (FDA, \%), nutrientes digestíveis totais (NDT, \%), energia líquida de lactação (ELL, kcal kg-1 MS).

\section{AGRADECIMENTOS}

Ao Conselho Nacional de Desenvolvimento Científico e Tecnológico (CNPQ) pela concessão de bolsas de Produtividade em Pesquisa para o segundo e sexto autores.

\section{REFERÊNCIAS}

ANFAR. Compêndio Brasileiro de Alimentação Animal Métodos Analíticos. São Paulo, 2009. 204p.

BAL, M.A. et al. Stage of maturity, processing, and hybrid effects on ruminal in situ disappearance of whole - plant corn silage. Animal Feed Science and Technology, v.86, p.83-94,
2000. Disponível em: <http://www.uwex.edu/ces/dairynutrition/ documents/csinsituafst.pdf $>$. Acesso em: 25 set. 2011.

BALBINOT JÚNIOR, A.A.; FLECK, N.G. Competitividade de dois genótipos de milho (Zea mays) com plantas daninhas sob diferentes espaçamentos entre fileiras. Planta Daninha, v.23, p.415-421, 2005. Disponível em: <http://www.scielo.br/pdf/pd/ v23n3/a04v23n3.pdf>. Acesso em: 25 set. 2011. doi: 10.1590/ S0100-83582005000300004.

BELEZE, J.R.F. et al. Avaliação de cinco híbridos de milho (Zea mays, L.) em diferentes estádios de maturação, produtividade, características morfológicas e correlações. Revista Brasileira de Zootecnia, v.32, p.529-537, 2003. Disponível em: <http://www. 
scielo.br/pdf/rbz/v32n3/a04v32n3.pdf>. Acesso em: 25 set. 2011. doi: 10.1590/S1516-35982009000200006.

CORRÊA, C.E. et al. Relationship between corn vitreousness and ruminal in situ starch degradability. Journal of Dairy Science, v.85, n.11, p.3008-3012, 2002.

DELALIBERA, H.C. et al. Resistência de grãos de milho à ruptura por compressão. Ciência Rural, v.38, p.2493-2497, 2008. Disponível em: <http://www.scielo.br/pdf/cr/v38n9/a12v38n9. pdf $>$. Acesso em: 25 set. 2011.

FLARESSO, J.A. et al. Cultivares de milho (Zea mays L.) e sorgo (Sorghum bicolor (L.) Moench.) para ensilagem no Alto Vale do Itajaí, Santa Catarina. Revista Brasileira de Zootecnia, v.29, p.1608-1615, 2000. Disponível em: <http://www.scielo.br/pdf/ rbz/v29n6/5686.pdf>. Acesso em: 25 set. 2011.

HARLAN, D.W. et al. Detergent fiber traits to predict productive energy of forages fed free choice to non lactanting dairy cattle. Journal Dairy Science, v.74, p.1337-1353, 1991. Disponível em: <http://agris.fao.org/agris-search/search/display. do?f $=1991 \% 2 F U S \% 2 F U S 91154 . x m l \% 3 B U S 9130277>$. Acesso em: 25 set. 2011.

JAREMTCHUK, A.R. et al. Características agronômicas e bromatológicas de vinte genótipos de milho (Zea mays L.) para silagem na região leste paranaense. Acta Scientiarum Animal Sciences, v.27, p.181-188, 2005. Disponível em: <http://periodicos. uem.br/ojs/index.php/ActaSciAnimSci/article/viewArticle/1220>. Acesso em: 25 set. 2011. doi: 10.4025/actascianimsci.v27i2.1220.

MAACK, R. Geografia física do Estado do Paraná. Curitiba: Banco de desenvolvimento do Paraná, 1968. 350p.

MELLO, R; NÖRNBERG, J.L. Fracionamento dos carboidratos e proteínas de silagens de milho, sorgo e girassol. Ciência Rural, v.34, p.1537-1542, 2004. Disponível em: <http://www.scielo.br/ pdf/cr/v34n5/a33v34n5.pdf>. Acesso em: 25 set. 2011.

MERTENS, D.R. Análise da fibra e sua utilização na avaliação de alimentos e formulação de rações. In: SIMPÓSIO INTERNACIONAL DE RUMINANTES, 1992, Lavras, MG. Anais... Lavras: SBZ-ESALQ, 1992. p.188.

MITTELMANN, A. et al. Avaliação de híbridos comerciais de milho para utilização como silagem na região sul do Brasil. Ciência Rural, v.35, p.684-690, 2005. Disponível em: <http:// www.scielo.br/pdf/cr/v35n3/a32v35n3.pdf>. Acesso em: 25 set. 2011.

MORAES, G.J. et al. Produtividade e valor nutritivo das plantas de milho de textura dentada ou dura em três estádios de colheita para silagem. Boletim da Indústria Animal, v.65, n.2, p.155-166, 2008.
MORAES, G.J. et al. Produtividade e valor nutritivo das plantas de milho de textura dentada ou dura em três estádios de colheita para silagem. Boletim da Indústria Animal, v.65, n.2, p.155-166, 2008. Disponível em: <http://www.iz.sp.gov.br/ pdfsbia/1216050624.pdf>. Acesso em: 25 set. 2011.

NEUMANN, M. et al. Comportamento de híbridos de milho (Zea mays) s sorgo (Sorghum bicolor) para silagem na região centro-sul do Brasil. Revista do setor de Ciências Agrárias e Ambientais, v.4, p.237-251, 2008. Disponível em: <http://www.unicentro.br/ editora/revistas/ambiencia/v4n2/artigo\%205.pdf>. Acesso em: 25 set. 2011

OLIVEIRA S.J. et al. Adaptabilidade e estabilidade de cultivares de milho destinados à silagem em bacias leiteiras do Estado de Goiás. Pesquisa Agropecuária Tropical, v.37, p.45-50, 2007. Disponível em: <http://www.revistas.ufg.br/index.php/pat/article/ view/1864>. Acesso em: 25 set. 2011.

OLIVEIRA, J.S. et al. Estratificação de ambientes, adaptabilidade e estabilidade de híbridos comerciais de milho para silagem no sul do Brasil. Ciência Rural, v.34, p.997-1003, 2004. Disponível em: <http://www.scielo.br/pdf/cr/v34n4/a05v34n4.pdf>. Acesso em: 25 set. 2011. doi: 10.1590/S0103-84782004000400005.

ROSSI JÚNIOR, P. et al. Digestibilidade aparente de dois cultivares de milho, cortados em diferentes alturas, submetidos à ensilagem. Arquives of Veterinary Science, v.11, p.58-61, 2006. Disponível em: <http://ojs.c3sl.ufpr.br/ojs2/index.php/veterinary/ article/viewArticle/7428>. Acesso em: 25 set. 2011.

SANTOS, H.G. et al. Distribuição e ocorrência dos solos no Estado do Paraná. In: BHERING, S.B.; SANTOS, H.G. dos (Eds.) Mapa de solos Estado do Paraná: legenda atualizada. Rio de Janeiro: Embrapa Solos; Colombo: Embrapa Florestas; Londrina: Instituto Agronômico do Paraná, 2008. p.49-74.

SENGER, C.C.D. et al. Composição química e digestibilidade in vitro de silagens de milho com distintos teores de umidade e níveis de compactação. Ciência Rural, v.35, p.1393-1399, 2005. Disponível em: <www.scielo.br/pdf/cr/v35n6/a26v35n6.pdf>. Acesso em: 25 set. 2011. Acesso em: 25 set. 2011. doi:10.1590/ S0103-84782005000600026.

SILVA, A.V. et al. Composição bromatológica e digestibilidade in vitro da matéria seca de silagens de milho e sorgo tratadas com inoculantes microbianos. Revista Brasielira de Zootecnia, v.34, p.1881-1890, 2005. Disponível em: <http://www.scielo.br/pdf/ rbz/v34n6/27240.pdf>. Acesso em: 25 set. 2011. doi:10.1590/ S1516-35982005000600011.

VILELA, H.H. et al. Valor nutritivo de silagens de milho colhido em diversos estádios de maturação. Revista Brasileira de Zootecnia, v.37, p.1192-1199, 2008. Disponível em: <http://www. scielo.br/pdf/rbz/v37n7/08.pdf>. Acesso em: 25 set. 2011. doi: S1516-35982008000700008. 